\title{
Carnets
}

Revue électronique d'études françaises de l'APEF

Première Série - 2 Numéro Spécial | 2010

Littératures nationales: suite ou fin. Résistances, mutations \& lignes de fuite

\section{A quinta de Fiama Sob o Olhar de Medeia: aproximação à Natureza e aos mitos}

João Amadeu Oliveira Carvalho da Silva

\section{(2) OpenEdition}

Journals

Edição electrónica

URL: http://journals.openedition.org/carnets/5050

DOI: $10.4000 /$ carnets. 5050

ISSN: 1646-7698

Editora

APEF

Edição impressa

Data de publição: 1 Junho 2010

Paginação: 121-129

\section{Refêrencia eletrónica}

João Amadeu Oliveira Carvalho da Silva, «A quinta de Fiama Sob o Olhar de Medeia: aproximação à

Natureza e aos mitos », Carnets [Online], Première Série - 2 Numéro Spécial | 2010, posto online no dia

16 junho 2018, consultado o 01 maio 2019. URL : http://journals.openedition.org/carnets/5050 ; DOI : 10.4000/carnets. 5050 


\title{
A QUINTA DE FIAMA SOB O OLHAR DE MEDEIA \\ Aproximação à Natureza e aos mitos
}

\author{
JoÃo Amadeu Oliveira CARVAlHo da Silva \\ Universidade Católica Portuguesa \\ Faculdade de Filosofia de Braga \\ jamadeu@braga.ucp.pt
}

\begin{abstract}
Resumo
Sob o Olhar de Medeia e Cenas Vivas, dois livros de Fiama Hasse Pais Brandão, têm em comum uma revalorização da Natureza e do ciclo da vida contemplado diariamente nos rituais do campo. $\mathrm{Na}$ primeira das obras, o tempo de crescimento, maturação e amadurecimento contribuem para a formação do ser humano de forma equilibrada. Os dois livros valorizam e promovem um olhar atento e perscrutador sobre a Natureza, encontrando nos Mitos e na Arte uma função integradora do ser humano. Num tempo em que o indivíduo se evidencia pela diferença e pelo enclausuramento, os amplos horizontes da cultura e da palavra poética contribuem para uma visão mais harmoniosa do ser humano, inevitavelmente inscrita na Natureza.
\end{abstract}

\begin{abstract}
Sob o Olhar de Medeia and Cenas Vivas, by Fiama Hasse Pais Brandão, have both in common a revaluation of Nature and its life cycle, visible every day in the rituals of the fields. In the first work, the time for growing up, ripening and maturing contributes towards a balanced moulding of the human being. Both books value and promote an attentive and inquisitive look into Nature, finding in Myth and in Art an integrative function for the human being. In a time when the individual stands out through difference and reclusiveness, the wide horizons of culture and poetic words contribute to a more harmonious vision of the human being, inevitably written in Nature.
\end{abstract}

Palavras-chave: Natureza, Mitos, Cultura, Arte, Harmonia, Sociedade contemporânea Keywords: Nature, Myths, Culture, Art, Harmony, Contemporary society 
Ao longo da leitura de Sob o Olhar de Medeia e Cenas Vivas, dois livros de Fiama Hasse Pais Brandão, procuraremos entender a relação fundamental que a narrativa e a poesia mantêm com a Natureza, aproximação que, no primeiro daqueles dois livros, é consolidada pelos mitos da cultura grega. Em ambos os livros a temática sobre a Natureza assume uma centralidade significativa.

Numa época em que nos sentimos dispersos, sem raízes e sem um rumo forte, incapazes de promover aproximações e consolidar pontos de vista, abertos à volatilidade do futuro sem o tempero da memória, torna-se essencial que refundemos o nosso olhar e os nossos comportamentos numa estrutura matricial, o único ponto de partida aceitável e o único e indeclinável ponto de chegada. A Natureza é a nossa casa e por mais que nos queiramos afastar dela sempre lá voltamos, prodigamente. Depois de desbaratarmos muito, de cortarmos laços e esquecermos os cheiros e sabores naturais, reiniciamos gradualmente a viagem de regresso ao espaço de aconchego, mesmo que o caminho se faça de forma titubeante e variada. Torna-se necessária uma reconciliação com os princípios vitais, o reconhecimento de que toda a actividade humana sempre terá a sua origem na Natureza e será esta a propiciar os momentos de harmonia e a percepção de unidade que cada vez mais se tornam essenciais para a sobrevivência física e mental do ser humano.

Nos textos de Fiama Hasse Pais Brandão, encontramos mais do que ligeiras referências à paisagem, suaves aproximações, breves metáforas alimentadas pela natureza. Pelo enredo da sua narrativa, pelos espaços luminosos da sua poesia, convivemos com os elementos primordiais, constroem-se momentos de harmonia, encontra-se um sentido mais profundo para a vida e para a morte, uma fonte de conhecimento que contribui para a solução de alguns dos problemas da sociedade pós-moderna ${ }^{1}$.

A aproximação de Sob o Olhar de Medeia à cultura grega, à cultura hebraica (com referências ao Novo Testamento) e à cultura popular, centra-se no mundo dos mitos, como forma de entender um sentido mais profundo do quotidiano e uma relação mais intensa com a Natureza. Nos tempos que vivemos, impõe-se o reconhecimento e a solidez de uma cultura e suas raízes para que não se esbata a identidade matricial e se reconheçam ainda os fundamentos da nossa existência. O caldo multicultural em que vivemos exige um banho na profundidade do passado, de forma a encontrarmos as mais profundas raízes que nos aproximam e nos distinguem. Nessa perspectiva, os mitos representam a assimilação compreensiva, à custa da força transformadora do olhar de Medeia, aglutinadora e repositora de valores. O seu olhar "é a ponte entre o primordial e o transcultural, o elo que nos permite transpor fronteiras de tempo e de espaço, numa [correlação] de homens, culturas, religiões e ideologias, por força da sua capacidade transfiguradora" (Borges, 2003:

\footnotetext{
${ }^{1}$ A relação entre a necessidade de consumir e a felicidade afastou o homem da Natureza: "Marta concluiria que criar desejos e necessidades é um vício de educação, perverso e sem piedade” (Brandão, 2008: 167).
} 
148).

Sob o Olhar de Medeia é uma longa narrativa que tem Marta como protagonista. O narrador heterodiegético acompanha-a, desde os seus primeiros anos de vida, até à idade adulta e vai amavelmente combinando as falas amadurecidas, feitas "da memória dos factos e da memória de outros pensamentos" (Brandão, 2008: 195), com o momento ainda imaturo dos actos da sua infância. Depois de ter sido afastada do quarto materno aos quatro anos ${ }^{2}$ (cf. Brandão, 2008: 156-157; 160), Marta passa a encontrar na quinta e nos afazeres diários do campo o espaço com o qual se começa a identificar profundamente e do qual pretende recolher todo o conhecimento. "Os sopros do vento, os estalidos das árvores, o eco do jorro de água do tanque, tudo a enchia de emoção e, de certo modo, compensava a perda. Sentia-se grata ao vento e à água pela quebra do silêncio da casa" (Brandão, 2008: 170).

O espaço reduzido e não individualizado do quarto da mãe é assim substituído pela amplitude da quinta, pelo espaço materno da Natureza, assumindo-se como uma verdadeira oportunidade de aprendizagem. Através da atenção e disponibilidade do Caseiro, e na escola com a ajuda do Professor que se eleva como a voz dos mitos ancestrais, dá-se a iniciação ao conhecimento da Natureza. "O sentimento do exílio tornava-se, a pouco e pouco, autoconhecimento" (Brandão, 2008: 187) e Marta acaba por compreender que esse exílio servirá para a iniciar no "inato sofrimento, que ocupa, com a alegria, metade da nossa vida" (Brandão, 2008: 286).

Uma outra personagem igualmente necessária, embora distinta por simbolizar o Mal, é Lázaro, o filho do Caseiro com a mesma idade de Marta. Proporciona à protagonista a experiência e a construção de uma personalidade amadurecida pelas experiências de desarmonia e ruptura com que é forçada a conviver, quando o vê a afugentar as ovelhas, a matar os coelhos rejeitados pela mãe ou ao atirar-lhe, ao cão da quinta, o frágil gato recolhido. A percepção e a interiorização da ausência e da perda são muitas vezes sentimentos alimentados pela mão perversa do seu companheiro da quinta. Esta personagem desperta Marta para a alternância dos contrários e para a construção da "harmonia entre o sofrimento e a esperança" (Brandão, 2008: 164).

A aceitação da vida e a interiorização da degradação e morte advêm-lhe da Natureza, transmitidas directamente pelas vivências e absorvidas ao longo da infância. A colheita da vida pujante dos frutos exigia o encanto do colector e por isso Marta considerava que Lázaro não deveria colher as nêsperas, porque não sabia "deslumbrar-se com o ciclo da vida" (Brandão, 2008: 193). A actividade mais simples ou mais complexa representava, aos olhos daquela personagem feminina, um ritual, uma experiência ancestral, uma anulação

\footnotetext{
${ }^{2} \mathrm{O}$ afastamento marcante do quarto materno é assemelhado intertextualmente ao que sucedeu com a protagonista da novela Menina e Moça de Bernardim Ribeiro, quando a levaram de casa de sua mãe (cf. Brandão, 2008: 149; 151-152; 157).
} 
dos tempos, num espaço de harmonia, onde se representa um acontecimento da história geral da humanidade, uma fonte inesgotável de gestos e saberes, como sucede com a tosquia das ovelhas (cf. Brandão, 2008: 197): "É uma cadência eterna. Tosquiar a lã do gado é uma das leis naturais da Primavera" (Brandão, 2008: 200). A colheita das ameixas é outro dos momentos iniciáticos (cf. Brandão, 2008: 201-202): "No novo louvor das árvores [...] entre as que já haviam dado fruto as ameixas eram as que maior tributo prestavam à água e à terra, de onde extraíam a sua suavidade e a sua força" (Brandão, 2008: 202). A colheita dos marmelos e a laboração da marmelada, a recolha das uvas e o mosto também se encontravam associados ao mesmo ritual (cf. Brandão, 2008: 208-208; 212).

Marta "[r]econhecia que a mutação era uma das formas de o Universo agir, e esse reconhecimento, ainda criança, encheu-a de surpresa e de sentido de comunhão com os elementos" (Brandão, 2008: 209). Dava-se uma transformação alquímica a partir dos elementos da Natureza, evocava-se um "afinamento espiritual" (Brandão, 2008: 212) da matéria ou a morte pela queda dos frutos à terra de forma a contribuírem para a vida de novos frutos que, desse modo, "passavam a participar no tempo da vida ilimitada" (Brandão, 2008: 218). A transmutação da matéria e a depuração dos elementos exigia a perda e a ausência aparente. Assim, compreendeu o desaparecimento do seu gato e "[s]entia-se feliz com a morte, porque compreendera que a grande árvore sempre manteria consigo um duplo diálogo, o de si mesma, a palmeira, e o de parte do seu corpo, o gato" (Brandão, 2008: 262).

A morte deixa de ser a representação da ruptura para significar um momento da eternidade. Quando a avó morre, Marta percebe que ela passa a depender da juventude para se renovar e subsistir e assemelha-a a uma planta que lança gavinhas e folhas novas (cf. Brandão, 2008: 270) e por isso prefere vê-la "enterrada na terra, a germinar" (Brandão, 2008: 274). Todo o ambiente da aldeia, os trabalhos diários ou os encontros sociais, porque se concretizam rente à terra, reflectem uma harmonia que pode também encontrar-se nos sons populares e antigos, no ritmo da dança. "O chão de pedras, quente do Sol diurno, distende e molda os músculos das pernas para o ritmo do som, uma ligação entre a música da terra, a deste povoado concreto, e os astros, o todo" (Brandão, 2008: 301).

Mas entre os bens da Natureza, também se pode encontrar a solidão.

Durante toda a sua vida seria sempre essa, a solidão no meio da Natureza, a mais dura, talvez por ser uma falta de harmonia essencial em relação à Natureza. Esta é infinitamente múltipla e articulada entre si, tudo depende de tudo e as espécies, animais ou vegetais, associam-se, funcionam em comum. E também a espécie humana, quanto mais próxima da Natureza mais gregária é nos conjuntos, mais coesa no todo. Marta não tinha ainda pensamentos teóricos claros, quando ficou só na Quinta, o território da infância e da juventude. Faltava-Ihe pensar a relação 
fundamental do trabalho em comum, do afecto partilhado, das surpresas, entre 0 nascer e florir, o madurar, o colher, o secar, o morrer, o renascer, o reflorir, o sempre (Brandão, 2008: 243-244).

Ao contacto de Marta com a Natureza está associada uma perspectiva de compreensão mais abrangente e universal. O gosto pela literatura clássica e pelos mitos facilita-Ihe a transferência de conhecimentos adquiridos indutivamente para um espaço mais amplo.

Em permanente reajustamento, Marta vivia e revivia no mundo, desde as primeiras configurações até aos mitos. Uns anos foram vividos a receber os dons e as privações; outros anos, passados a contrastar recordações e a escolher a partir delas valores. Outros anos, intensos, transformou em símbolos cada acto (Brandão, 2008: 208).

Há uma estrutura de vasos comunicantes entre o contacto directo com a Natureza e o conhecimento dos mitos, de forma a perscrutar, por detrás das atitudes simples da quinta, a complexidade da vida e dos sentimentos (cf. Brandão, 2008: 239). Será também esta dupla convivência que lhe permitirá verbalizar um certo desagrado relativamente ao caminho que segue a humanidade em finais do século XX e enunciar uma proposta de acerto onde se possam combinar a memória do passado, a Natureza e o avanço tecnológico. "Relativizar o laicismo moderno, a ideia moderna de progresso evolucionista, relativizar, queria dizer, reduzir, trabalhar para isso, um ideal sem absolutos, um futuro entrelaçado ao passado, sem a voragem tecnológica que isola o futuro" (Brandão, 2008: 327-328) de forma a evitar a autonomização progressiva do indivíduo que insistentemente constrói abismos à sua volta e se assume tragicamente solitário.

O olhar de Marta não será o do Caseiro, Tobias que conduz a criança, nem o de Maria, sua amiga das fainas agrícolas e das corridas pela praia. Marta aprende com Medeia (cf. Brandão, 2008: 219) a olhar mais profundamente para a Natureza sem, no entanto, se afastar dela. "Pensa, sentada no refúgio do banco de pedra isolado, que o olhar é poderoso, que recebe e transmite o mundo visto. Mais tarde, sem jamais esquecer Medeia, pensa que é essa a definição da Arte, ao lançar imagens de vida e de morte, as únicas possíveis na Terra" (Brandão, 2008: 220), sendo que, "[n]a Arte e na memória dos homens, a morte era uma permanência na vida" (Brandão, 2008: 244). 


\section{O olhar de Medeia em Cenas Vivas}

O olhar perscrutador e envolvente da poetisa perante a Natureza permitirá que dos seus poemas se criem cenas vivas, libertando-as da performatividade e evanescência das imagens fugazes da sociedade contemporânea. O contacto com a quinta, as experiências vividas, os conhecimentos práticos adquiridos por Marta em Sob o Olhar de Medeia são absorvidos em alguns dos poemas de Cenas Vivas, saindo reforçada a relação entre a Natureza e a arte, na obra da autora. Para Marta não será inesperado o reconhecimento da arte como fenómeno apaziguador e acalentador diante dos cuidados diários. "Por vezes só o dom poético ou artístico submete a angústia e permite uma procura serena" (Brandão, 2008: 161).

Recolhemos da poesia de Fiama essa sensação de serenidade, de aceitação da vida e uma compreensão dos efeitos do tempo sobre o ser humano que o levam a reconhecer, à semelhança da "história geológica da Terra", a história "dos lugares que se uniam ao Tempo" (Brandão, 2000: 22). O tempo lento de maturação trouxe ao sujeito lírico a sábia convivência com a Natureza, sabendo retirar dela a sabedoria que o aconselha a olhar para o futuro com a memória dos tempos ancestrais, assim "Todos os que morreram aqui são contemporâneos / dos cepos e dos troncos que anualmente / regressam à vida" (Brandão, 2000: 74).

O olhar de Medeia, realizado na poética de Fiama, concretiza-se na sua perscrutadora atenção aos pormenores. Depurada das grandes emoções, a sua poesia transforma-se numa linguagem dos gestos e do rosto (cf. Brandão, 2000: 84) "E as suas palavras [são] / as do reconhecimento das coisas, minuciosas" (Brandão, 2000:). O que "da realidade lhe absorve o olhar é sempre um laivo de alguma breve graça da natureza, 'uma vaga de luz, um pavio, uma sombra incerta': não a intensidade da experiência, antes a singeleza, a graciosidade, o pormenor, inapreensível para um olhar superficial" (Silva, 2004: 291).

A obra de Fiama ensina-nos a atribuir ao circunstancial o protagonismo de cada momento, quando força o olhar sobre o que nos cerca e esboça uma atitude compreensiva e harmoniosa entre aquele que vê e o que é visto. Assim, entrega-se a cada espaço como se ele contivesse a totalidade do tempo.

$\mathrm{O}$ apego às pequenas coisas e o convívio em profundidade com o tempo representam uma fuga da solidão trágica de que o ser humano contemporâneo tem consciência. A relação com as flores do jardim e com os animais da quinta é a ponte para o outro e o reconhecimento do homem como um ser gregário que se completa na comunhão com todos aqueles que o rodeiam. A poetisa e Marta disponibilizam a sua atenção e compartilham as suas emoções com a Natureza e esta retribui-Ihes uma paz e um bem- 
estar que as confortam. "Só na alegria e no sossego, a Natureza se identificava, nas suas várias figuras, com o seu íntimo. Um dia [Marta] sentirá que a Arte é uma forma dessa alegria, chamando a si a Natureza, que ludicamente se aproxima" (Brandão, 2008: 163).

Será pela palavra que o ser humano se estrutura, consolida e preenche o abismo que o afasta dos outros. A linguagem representará simultaneamente a fronteira e a ponte para o outro.

$\mathrm{Na}$ linguagem, o homem joga, ao mesmo tempo, o processo de inspecção, decifragem e elaboração mítico-poiética, convertendo a sua relação com o meio ambiente (Umwelt) num mundo próprio (Welt). [...]. É pelo processo mítico-poiético que o homem se liberta das coacções inerentes às particularidades da sua existência individual e acede à generalidade do sentido que as informa (Rodrigues, 1999: 106).

Também, em Sob o Olhar de Medeia, Marta, ao apossar-se da linguagem própria, no contacto com os familiares, com o Caseiro e, finalmente na escola, com o professor, vai construindo uma peculiar forma de lidar com o mundo, de o entender e de se libertar das condicionantes espaço-temporais que determinariam uma visão redutora da realidade. Marta cresce e liberta-se. Para a sua visão do mundo, contribuem as narrativas clássicas que a preparam e lhe proporcionam o sentido do futuro (cf. Brandão, 2008: 239). O enriquecimento da linguagem e a abertura para novas realidades e culturas permitem-Ihe uma melhor compreensão do seu passado. "Como se só a cultura adquirida a fizesse reviver actos e memórias de uma infância muda. E, mais tarde, narraria de novo o que já narrara, porque um novo pensamento, ou melhor, memória de um mito a faria tentar descrever com maior acuidade o que antes mais imprecisamente descrevera e vivera" (Brandão, 2008: 239). O domínio da linguagem e da cultura contribuem para uma maior compreensão do homem e para uma consistente percepção da liberdade pessoal, já que o conhecimento e a compreensão do passado libertam, em vez de aprisionarem.

Marta tentara sempre encontrar a verdadeira conciliação entre o dia a dia das tarefas tradicionais e a meditação dos mitos clássicos e bíblicos, e evangélicos, numa aculturação posterior. A Maria e o Lucas pertenciam à sua constelação caseira, lugar do habitar geográfico. Amava-os pela sua insciência, o seu saber, tal como o do Caseiro, vindo de antepassados. Só tinham ido à escola para ajudarem os pais, e possuíam a bem-aventurança dessa ajuda, que, na juvenilidade deles, era até arrogância e, por outro lado, autodesprezo" (Brandão, 2008: 282).

A preparação cultural de Marta facilita o acesso a um grau superior de harmonia que se distingue daquele em que ficam os seus amigos das lides da quinta que entendem mais o 
que vêem e sentem e menos o que, do contacto com realidade, permite a criação de laços entre tempos e espaços diversos. O ser humano deve entender que não se realiza, enquanto indivíduo, sem uma disponibilidade para se desenvolver em contacto com os outros, com a natureza, com a cultura e com a arte.

Os abismos e os silêncios pesados que se vivem no presente poder-se-ão diluir com a redescoberta da Natureza e com a revalorização das nossas raízes e será pela linguagem e pela arte que se derrubarão as fronteiras e se anularão as distâncias que só têm sentido para os que receiam perder o que pensam possuir. Como afirma Gadamer, ao comentar a Propedêutica de Hegel, "[r]econhecer no estranho o que é próprio, familiarizar-se com ele, eis o movimento fundamental do espírito, cujo ser é apenas o retorno a si mesmo a partir do ser diferente" (Gadamer, 2002: 54) ou então como sugere Fiama Hasse Pais Brandão, com um olhar poético: "São as flores do jardim que guardam o enigma, / pois cada espécie vista tem em si / um sinal visível de outra estação. / Flores solitárias que, uma a uma, vêm / ligarse a fragmentos de vida antiga" (Brandão, 2000: 107). 


\section{Bibliographie}

AA, VV (2001). Fiama Hasse Pais Brandão. In: Relâmpago, o 8 (número monográfico).

BORGES, Anabela Ferreira (2003). O Tempo e o Mito em Sob o Olhar de Medeia, (Dissertação de Mestrado, policopiada). Viseu: Faculdade de Letras - UCP.

Brandão, Fiama Hasse Pais (2000). Cenas Vivas. Lisboa: Relógio d'Água.

BRANDÃo, Fiama Hasse Pais (2008). Em Cada Pedra um Voo Imóvel: O Aquário, O Retratado, Falar Sobre o Falado, Sob o Olhar de Medeia. Lisboa: Assírio \& Alvim.

CoelHo, Eduardo Prado (1988). A Noite do Mundo, col. "Estudos e Temas Portugueses". Lisboa: Imprensa Nacional - Casa da Moeda.

Cruz, Gastão (1973). A Poesia Portuguesa Hoje. Lisboa: Plátano Editora.

GADAMER, Hans-Georg (2002). Verdade e Método. Petrópolis: Editora Vozes.

RODRIGUES, Adriano Duarte (1999). Comunicação e Cultura - A Experiência Cultural na Era da Informação. Lisboa: Editorial Presença.

SILVA, João Amadeu Oliveira Carvalho da (2004). "A Poesia de Fiama Hasse Pais Brandão - Um Modo de Tratar a Realidade Por Tu". In: Revista Portuguesa de Humanidades, vol. 8 -1/2. Braga: Faculdade de Filosofia, pp. 281-313. 
